\title{
Gly-tRF enhances LCSC-like properties and promotes HCC cells migration by targeting NDFIP2
}

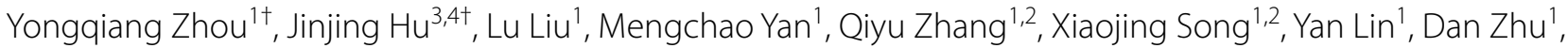
Yongjian Wei ${ }^{1}$, Zongli Fu', Liming $\mathrm{Hu}^{4}$, Yue Chen ${ }^{1}$ and $\mathrm{Xun} \mathrm{Li}^{1,2,3^{*}}$

\begin{abstract}
Background: Accumulating evidence demonstrates that tRFs (tRNA-derived small RNA fragments) and tiRNAs (tRNA-derived stress-induced RNA), an emerging category of regulatory RNA molecules derived from transfer RNAs (tRNAs), are dysregulated in in various human cancer types and play crucial roles. However, their roles and mechanisms in hepatocellular carcinoma (HCC) and liver cancer stem cells (LCSCs) are still unknown.
\end{abstract}

Methods: The expression of glycine tRNA-derived fragment (Gly-tRF) was measured by qRT-PCR. Flow cytometric analysis and sphere formation assays were used to determine the properties of LCSCs. Transwell assays and scratch wound assays were performed to detect HCC cell migration. Western blotting was conducted to evaluate the abundance change of Epithelial-mesenchymal transition (EMT)-related proteins. Dual luciferase reporter assays and signalling pathway analysis were performed to explore the underlying mechanism of Gly-tRF functions.

Results: Gly-tRF was highly expressed in HCC cell lines and tumour tissues. Gly-tRF mimic increased the LCSC subpopulation proportion and LCSC-like cell properties. Gly-tRF mimic promoted HCC cell migration and EMT. Loss of Gly-tRF inhibited HCC cell migration and EMT. Mechanistically, Gly-tRF decreased the level of NDFIP2 mRNA by binding to the NDFIP2 mRNA 3' UTR. Importantly, overexpression of NDFIP2 weakened the promotive effects of Gly-tRF on LCSC-like cell sphere formation and HCC cell migration. Signalling pathway analysis showed that Gly-tRF increased the abundance of phosphorylated AKT.

Conclusions: Gly-tRF enhances LCSC-like cell properties and promotes EMT by targeting NDFIP2 and activating the AKT signalling pathway. Gly-tRF plays tumor-promoting role in HCC and may lead to a potential therapeutic target for HCC.

Keywords: Hepatocellular carcinoma, Liver cancer stem cells, tRNA-derived fragments, NDFIP2, EMT, AKT

\section{Background}

Hepatocellular carcinoma (HCC) is one of the most common malignant tumours, causing a substantial global health burden [1]. Reasonable methods of prevention,

\footnotetext{
*Correspondence: lix@lzu.edu.cn

${ }^{\dagger}$ Yongqiang Zhou and Jinjing Hu contributed equally to this work ${ }^{1}$ The First Clinical Medical College of Lanzhou University, Lanzhou University, 222 Tianshui South Road, Lanzhou 730000, China

Full list of author information is available at the end of the article
}

monitoring, early detection, diagnosis and treatment have been developed [2], however, the survival of HCC patients after radical resection is poor [3]. Investigation of the underlying mechanisms of HCC invasiveness and metastasis is of great significance for finding new therapeutic targets that can improve the prognosis of HCC.

Newly discovered types of noncoding RNAs (ncRNAs) derived from pre-transfer RNA (tRNA) or mature tRNA by precise site-specific cleavage are tRFs (tRNA-derived original author(s) and the source, provide a link to the Creative Commons licence, and indicate if changes were made. The images or other third party material in this article are included in the article's Creative Commons licence, unless indicated otherwise in a credit line to the material. If material is not included in the article's Creative Commons licence and your intended use is not permitted by statutory regulation or exceeds the permitted use, you will need to obtain permission directly from the copyright holder. To view a copy of this licence, visit http://creativecommons.org/licenses/by/4.0/. The Creative Commons Public Domain Dedication waiver (http://creativeco mmons.org/publicdomain/zero/1.0/) applies to the data made available in this article, unless otherwise stated in a credit line to the data. 
small RNA fragments) and tiRNAs (tRNA-derived stressinduced RNA) [4]. Abnormal expression of tRFs and tiRNAs has been observed in many diseases, including tumours, neurodegenerative diseases, and metabolic and infectious diseases $[5,6]$. tRFs and tiRNAs have been detected in a variety of body fluids and tissues [7], and their expression are highly abundant $[8,9]$, heavily modified and not easily degraded [10]; thus, they are more stable than other ncRNAs and increasingly becoming a popular topic in oncology research [11]. Accumulating evidence shows that tRFs and tiRNAs play crucial roles in human cancers, including breast cancer [12-15], prostate cancer [16, 17], and colorectal cancer $[18,19]$, by participating in multiple biological functions, including gene expression and silencing, translation regulation and epigenetic regulation [20].

A recent study showed that glycine tRNA-derived fragment (Gly-tRF) expression is upregulated in ethanol-fed mice and promotes alcoholic fatty liver disease (AFLD) [21]. AFLD is one of the early forms of liver injury. Some patients with simple steatosis can develop more severe forms of liver injury, including steatohepatitis, cirrhosis, and eventually HCC [22]. Here we aimed to explore the impact of Gly-tRF on the biological process of HCC and the roles of Gly-tRF in LCSC.

In the present study, Gly-tRF was found to be upregulated in HCC tissues and cell lines, and increased expression of Gly-tRF triggers EMT and the acquisition of LCSC-like properties.

Furthermore, target genes prediction and Dual luciferase reporter assays indicated that NDFIP2 was a direct target of Gly-tRF. Subsequently, we observed that overexpression of NDFIP2 weakened the promotive effects of Gly-tRF on EMT and LCSC-like cell sphere formation ability. Finally, bioinformatics analysis indicated that GlytRF functions by activating the AKT signalling pathway (A flowchart of the article is shown in Additional file 1: Figure S1). Therefore, this study illustrates that Gly-tRF plays tumor-promoting role in $\mathrm{HCC}$ and may lead to a potential therapeutic target for HCC.

\section{Materials and methods}

\section{Specimen collection, tissue microarray}

\section{and immunohistochemical staining}

Fifteen samples of histologically confirmed tumours and matched adjacent non-tumour tissues obtained from HCC patients who underwent radical hepatectomy at Lanzhou University First Hospital. The study was approved by the hospital ethics committee, and according to the institutional review committee's procedures, all patients signed an informed consent form before the study. A tissue microarray containing 90 tumour tissues and matched adjacent non-tumour tissues was purchased from Shanghai Outdo Biotech Co., Ltd (Shanghai, China). All patients provided written informed consent and were followed up for 5-6 years with clear prognostic information. Immunohistochemical staining was performed as previously described [23]. For immunohistochemical images, two experienced pathologists independently performed immunohistochemical staining scores according to the staining intensity ( 0 : no staining; 1 : weak staining; 2: moderate staining; 3 : strong staining) and the percentage of positive cells $(0: 0 \% ; 1:<25 \% ; 2: 26-50 \% ; 3:>50 \%)$. The staining intensity score and the staining percentage score were summed to calculate the final immunohistochemical score. We defined an immunohistochemical of score 0 to 4 as low expression and a score of 5 to 6 as high expression.

\section{Cell culture}

The human liver cancer cell lines HepG2, Huh7 and HCCLM3 were purchased from the China Center for Type Culture Collection (CCTCC, Wuhan, China) and were identified by short tandem repeat (STR). L02 hepatocytes were gift from Zhongshan Hospital of Fudan University (Shanghai, China). The embryonic kidney cell line HEK-293 T was a gift from Shanghai GeneChem Co., Ltd. (Shanghai, China). All cells were grown in Dulbecco's modified Eagle's medium (DMEM; pH =7.2, Gibco Company, Grand Island, NY, USA) containing $10 \%(\mathrm{v} / \mathrm{v})$ foetal bovine serum (FBS, HyClone, Logan, UT, USA). All cells were cultured in a humidified incubator (Thermo Fisher Scientific, Waltham, MA, USA) at $37^{\circ} \mathrm{C}$ and $5 \% \mathrm{CO} 2$. All cells were tested for mycoplasma contamination.

\section{RNA isolation}

Total RNA was harvested from cells and tissues using RNAiso Plus (Takara Holdings Inc., Kyoto, Japan), and the protocol recommended by the manufacturer protocol was followed for isolation of total RNA. NanoDrop 2000 (Thermo Fisher Scientific) was used to measure the quality and quantity of the isolated RNA.

\section{$3^{\prime}$ and $5^{\prime}$ Adaptor ligation, first-strand complementary DNA (CDNA) synthesis and real-time PCR}

Heavy modifications contained in tRNAs, such as $3^{\prime}$-aminoacyl, $3^{\prime}-\mathrm{cP}, \mathrm{m} 1 \mathrm{~A}, \mathrm{~m} 1 \mathrm{G}$, and $\mathrm{m} 3 \mathrm{C}$ modifications will severely interfere with reverse transcription. Therefore, conventional PCR methods may not be able to reflect the true expression characteristics of tRNA-derived fragments [24]. In this work, an $\mathrm{rtStar}^{\mathrm{TM}}$ tRF\&tiRNA Pretreatment Kit (Arraystar Inc., Rockville, MD, USA. Cat \#AS-FS-005) was used to remove various modifications from Gly-tRF before $3^{\prime}$ and $5^{\prime}$ adaptor and cDNA synthesis. cDNA was synthesized using APExBIO First-strand cDNA Synsthesis Supermix (APExBIO Inc., Houston, 
TX, USA; Cat \#K1073). All steps, such as $3^{\prime}$-terminal deacylation, $3^{\prime}-\mathrm{cP}$ removal and $5^{\prime}-\mathrm{P}$ addition, demethylation and reverse transcription, were carried out in accordance with the manufacturer's instructions. All reactions were performed in an Mx3000P QPCR system (Agilent Technologies Inc., Santa Clara, CA, USA) using TB Green Premix Ex Taq II (Takara Holdings Inc., Kyoto, Japan) for real-time PCR according to the manufacturer's instructions. The primers are listed in Table 1. U6 or GAPDH was used as the normalized endogenous control for expression. The relative expression levels of Gly-tRF were analysed by the $2^{-\Delta \Delta \mathrm{Ct}}$ method.

\section{Cell transfection}

HCCLM3 and Huh7 cells were seeded in 6-well plates (Corning Life Sciences, USA) at a density of $4 \times 10^{5}$ cells per well. When the cells were $40-50 \%$ confluent, Gly-tRF negative control, Gly-tRF inhibitor, and Gly-tRF mimic lentiviruses were used to transduce cells according to the manufacturer's instructions (Shanghai GeneChem Co., Ltd, Shanghai, China). The sequences of all lentiviral products are shown in Table 1 . After $72 \mathrm{~h}$ of transduction, cells were cultured in complete medium containing $2 \mu \mathrm{g} / \mu \mathrm{L}$ puromycin for $72 \mathrm{~h}$. Cells stably transduced with Gly-tRF were used for subsequent experiments.

\section{Proportional staining analysis of representative LCSC markers}

HCC cells were prepared as single-cell suspensions for staining. All antibodies used for staining were purchased from Miltenyi Biotec (Bergisch Gladbach, Germany), and included a phycoerythrin (PE)-conjugated anti-CD133 antibody (Cat \#130-110-962), a PE-Vio770conjugated anti-CD13 antibody (Cat \#130-120-727), an allophycocyanin (APC)-conjugated anti-EpCAM antibody (Cat \#130-111-000), an APC-Vio770-conjugated

Table 1 Sequences information in this study

\begin{tabular}{|c|c|}
\hline Genes & Sequences \\
\hline \multirow[t]{2}{*}{ Gly-tRF } & GCAUUGGUGGUUCAGUGGUAGAAUUCUCGC \\
\hline & $\begin{array}{l}\text { Forward: CATTGGTGGTTCAGTGGTAGAAT } \\
\text { Reverse: AGTGCAGGGTCCGAGGTATT }\end{array}$ \\
\hline Gly-tRF NC-inhibitor & TTCTCCGAACGTGTCACGT \\
\hline Gly-tRF inhibitor & GCGAGAATTCTACCACTGAACCACCAATGC \\
\hline Gly-tRF NC-mimic & CON238 \\
\hline Gly-tRF mimic & $\begin{array}{l}\text { GCCTTGTTAAGTGCTCGCTTCGGCAGCACATATACTATGTTTGAATGAGGCTTC } \\
\text { AGTACTTTACAGAATCGTTGCCTGCACATCTTGGAAACACTTGCTGGGATT } \\
\text { ACTTCTTCAGGTTAACCCAACAGAAGGCTCGAGAAGGTATATTGCTGTTGA } \\
\text { CAGTGAGCGACGAGAATTCTACCACTGAACCACCAATGCTAGTGAAGCCAC } \\
\text { AGATGTAGCATTGGTGGTTCAGTGGTAGAATTCTCGCTGCCTACTGCCTCGCAA } \\
\text { TTCAAGGGGCTACTTTAGGAGCAATTATCTTGTTTACTAAAACTGAATACCTTG } \\
\text { CTATCTCTTTGATACATTTTTACAAAGCTGAATTAAAATGGTATAAATTAAATC } \\
\text { ACTTTTTTCAATTGGAAGACTAATGCGTTTAAACACGCGGCG }\end{array}$ \\
\hline NDFIP2 & $\begin{array}{l}\text { Forward: TCAAACCCAGCACCGCAGATTG } \\
\text { Reverse: CGCAGATAGCACCATACCTTCCAG }\end{array}$ \\
\hline ABHD17B & $\begin{array}{l}\text { Forward: GCTGCTTGGCTTGCTCTTAGGAC } \\
\text { Reverse: TTCAACCCAGAGAGGCTCCACAG }\end{array}$ \\
\hline KCNK10 & $\begin{array}{l}\text { Forward: ATGAAGTGGAAGACGGTGGTTGC } \\
\text { Reverse: AGTGGCTGCTGTTGTTGGAAGAG }\end{array}$ \\
\hline RNF103 & $\begin{array}{l}\text { Forward: TCATGGGTAAGGGCAGACTGGATG } \\
\text { Reverse: AAAGAAGCAATCGGGTGGAAGAGG }\end{array}$ \\
\hline CXXC4 & $\begin{array}{l}\text { Forward: TCCTCCTCCGCCTCCTCCTC } \\
\text { Reverse:TGGCAATTTGAAACGCACTGTCTG }\end{array}$ \\
\hline OXTR & $\begin{array}{l}\text { Forward: GGTGGTGGCAGTGTTTCAGGTG } \\
\text { Reverse: CAGGCAGCGAGCACGATGAC }\end{array}$ \\
\hline WDR44 & $\begin{array}{l}\text { Forward: CAGTGGAAGTCAAAGGAGGTGGTG } \\
\text { Reverse: GCCATGCTTGCGGTTAGGAGAG }\end{array}$ \\
\hline OSER1 & $\begin{array}{l}\text { Forward: AGCACCAGTCAGAACAGCAACAG } \\
\text { Reverse: TTGGGTAGCGTCAGAGGAGTCTTC }\end{array}$ \\
\hline GAPDH & $\begin{array}{l}\text { Forward: CCCACTAACATCAAATGGGG } \\
\text { Reverse: CCTTCCACAATGCCAAAGTT }\end{array}$ \\
\hline U6 & $\begin{array}{l}\text { Forward: CGCTTCGGCAGCACATATAC } \\
\text { Reverse: GAACGCTTCACGAATTTGCGT }\end{array}$ \\
\hline
\end{tabular}


anti-CD44 antibody (Cat \#130-113-339) and anti-REA control antibody (Cat \# 130-113-438, 130-113-440, 130113-434, 130-113-445). The percentages of $\mathrm{CD}_{133^{+}}$, $\mathrm{CD}_{13}{ }^{+}, \mathrm{EpCAM}^{+}$, and $\mathrm{CD} 44^{+}$within the HCC cell population were determined according to the manufacturer's instructions. In brief, $1 \times 10^{6}$ cells were centrifuged and resuspended in $98 \mu \mathrm{L}$ of buffer, $2 \mu \mathrm{L}$ antibody was added, and the cells were incubated for $10 \mathrm{~min}$ in the dark at $4{ }^{\circ} \mathrm{C}$. The cells were washed with $1 \mathrm{~mL}$ of buffer, centrifuged at $300 \mathrm{~g}$ for $10 \mathrm{~min}$, and resuspended in $400 \mu \mathrm{L}$ of buffer for detection. Data were acquired with a BD LSRFortessa. All samples were analysed in triplicate.

\section{Sphere formation assays}

Cells (2000 cells per well) were planted in a 6-well ultralow adhesion plate (Corning, USA). After 8 days of incubation, spheres were counted and photographed (15 random fields/well) under a stereomicroscope (Olympus, Tokyo, Japan). The diameter of the spheres was measured with Image-Pro Plus 6.0 software (Media Cybernetics Inc., Rockville, MD, USA), and colonies with a diameter greater than $20 \mu \mathrm{m}$ were considered positive for sphere formation.

\section{Transwell assays}

Cell migration experiments were performed in a 24-well Transwell plate $(8.0 \mu \mathrm{m}$ pore size, Corning Life Sciences, Costar, USA). Stably transduced cells were starved for $6 \mathrm{~h}$ in serum-free medium, trypsinized and adjusted to $2 \times 10^{5}$ cells $/ \mathrm{mL}$ after counting. Then, $600 \mu \mathrm{L}$ of complete medium containing $30 \%(\mathrm{v} / \mathrm{v})$ serum was added to the lower chamber, $200 \mu \mathrm{L}$ of the cell suspension was added to the upper chamber, and the cells were cultured for $48 \mathrm{~h}$. The cells in the upper chamber were removed, and the cells remaining on the membrane were fixed with $4 \%$ paraformaldehyde (Solarbio, Beijing, China). After staining with $0.5 \%$ crystal violet (Solarbio, Beijing, China), the cells were observed under a microscope and imaged. All experiments were repeated three times.

\section{Wound healing assay}

Stably transduced cells were trypsinized and seeded in a 6 -well plate. When the cells were $90 \%$ confluent, a 200 $\mu \mathrm{L}$ sterile pipette tip was used to uniformly make vertical scratches in the wells of the 6-well plate. Cells were removed by washing 3 times with PBS and multiple random fields were selected to observe cell migration at $0 \mathrm{~h}$, $24 \mathrm{~h}$, and $48 \mathrm{~h}$. The area and width of the scratches were quantified with Image-Pro Plus 6.0.

\section{Protein extraction and western blot analysis}

Western blotting was performed as previously described [25]. The primary antibodies used for Western blotting were as follows: anti-NDFIP2(1:1000, Bioss Antibodies Inc., Beijing, China; Cat \# bs-19059R), anti-pan AKT (1:1000, Abcam, Cambridge, UK; Cat \# ab8805), anti- phospho-AKT1 (1:1000, Abcam, Cat \# ab66138), anti-N-cadherin (1:1000, Abcam, Cat \# ab18203), antiE-cadherin (1:10,000, Abcam, Cat \# ab40772). An anti$\beta$-actin antibody (1:2000, Sigma, USA) was used as an internal control to ensure equal amounts of protein loading.

\section{Immunofluorescence staining}

Stably transduced cells were grown overnight on glass coverslips. The cells were fixed with $4 \%$ paraformaldehyde for $10 \mathrm{~min}$ at room temperature. The cells were washed 3 times with -cold PBS. The cells were then incubated with PBS (containing $0.3 \%$ Triton X-100) for $10 \mathrm{~min}$. The cells were washed 3 times with PBS for $5 \mathrm{~min}$ each. The cells were blocked 3\% BSA for $30 \mathrm{~min}$ at room temperature. The cells were then incubated with an antiNDFIP2 antibody (1:200, Bioss Antibodies Inc., Beijing, China; Cat \# bs-19059R) overnight at $4{ }^{\circ} \mathrm{C}$. The cells were washed 3 times with PBS-T, and were then incubated with Cy3-conjugated goat anti-rabbit (1:400, Servicebio, Wuhan, China; Cat \# GB21303) at room temperature in the dark for $60 \mathrm{~min}$. The cells were then incubated with 4',6-diamidino-2-phenylindole (DAPI, Servicebio) for 5 min. After washing with PBS, images were acquired using a fluorescence microscope (Nikon Eclipse C1; Nikon Corporation). Fluorescence quantitative analysis was performed using Image-Pro Plus 6.0.

\section{Plasmid construction, plasmid transfection and luciferase assay}

pcDNA3.1 was used as the vector to construct the NDFIP2 overexpression plasmid (pcDNA3.1+ NDFIP2 OE), and pGL6 (Beyotime, Shanghai, China) was used as the vector to construct the NDFIP2 3' UTR wild-type (NDFIP2 wt) and NDFIP2 3' UTR mutant (NDFIP2 mut) luciferase reporter plasmids. All constructed plasmids were verified by sequencing (TSINGKE, Beijing, China). The Renilla luciferase reporter plasmid pRL-TK and the pGL6 promoter empty vector were co-transfected with NDFIP2 wt or NDFIP2 mut into the HEK-293T cells in each well using Exfect Transfection Reagent (Vazyme Biotechnology Co., Ltd, Nanjing, China) following the manufacturer's instructions. In brief, $50 \mathrm{ng}$ of pRLTK and 400 ng of NDFIP2 wt, NDFIP2 mut or pGL6 were added to Opti-MEM, mixed with $1 \mu \mathrm{L}$ liposomes and incubated for $10 \mathrm{~min}$ at room temperature. Fortyeight hours after transfection, the cells were lysed, and a Dual-Luciferase ${ }^{\circledR}$ reporter analysis system (Promega, Madison, WI, USA) was used to perform dual-luciferase reporter assays. A GLOMAX 20/20 luminometer 
(Promega, Madison, WI, USA) was used to detect luciferase activity. All samples were analysed in triplicate. The same method was used to transfect HCCLM3 cells with pcDNA3.1+NDFIP2 OE and pcDNA3.1 empty vector (pcDNA3.1+vector). In brief, $3 \mu \mathrm{g}$ of pcDNA3.1 + NDFIP2 OE or pcDNA3.1 + vector and $9 \mu \mathrm{L}$ of liposomes were added to the cells. After $48 \mathrm{~h}$ of culture, follow-up experiments were performed.

\section{Bioinformatic analysis}

Gene expression profiles and clinical data were downloaded from the TCGA XENA database (https://xena. ucsc.edu/) to identify differentially expressed genes (DEGs) between HCC tissues and matched non-tumour tissues. Gene Ontology (GO) enrichment analysis was performed with the for DEGs.

\section{Statistical analysis}

GraphPad Prism 8 (La Jolla, CA, USA) was used for all statistical analysis and plotting. $\mathrm{P}<0.05$ was considered statistically significant. Student's $t$-test or one-way ANOVA was used for intergroup comparisons of quantitative data.

\section{Results}

\section{Gly-tRF expression is elevated in HCC}

The differential expression of Gly-tRF in L02 hepatocytes and HCC cell lines (HCCLM3, Huh7, HepG2) by were determined qRT-PCR. The expression of GlytRF in HCC cell lines was higher than that in L02 cells (Fig. 1A). In the $15 \mathrm{HCC}$ specimens, the expression of Gly-tRF in tumour tissues was elevated compared with that in adjacent non-tumour tissues (Fig. 1B). Based on the online database OncotRF (http://bioinformatics.zju. edu.cn/) [26], the median expression level of Gly-tRF in tumour tissues of HCC patients was higher than that in normal tissues (755.06RPM vs 655.40RPM) (Fig. 1C). The abnormal expression of Gly-tRF in HCC suggested that it might be involved in HCC progression. To evaluate the effect of Gly-tRF on HCC cell functions, Gly-tRF negative control, Gly-tRF inhibitor, and Gly-tRF mimic lentiviruses were transduced into HCCLM3 and Huh7 cells. We used qRT-PCR to confirm the Gly-tRF inhibitor blocked the expression of Gly-tRF in HCCLM3 and Huh7 cells (Fig. 1D, Fig. 1E). In addition, whether GlytRF mimic transduction boosts Gly-tRF expression was assessed (Fig. 1D, Fig. 1E).

\section{Gly-tRF is involved in the maintenance of LCSC-like properties}

The existence of liver cancer stem cells (LCSCs) is generally considered to be the primary cause of HCC metastasis, malignant growth and treatment failure
[27]. We investigated whether Gly-tRF has any effects on LCSCs. LCSC surface markers (CD133/CD13/ EpCAM/CD44) is often considered to represent the LCSC population [28]. We compared the percentages of $\mathrm{CD}_{133^{+}}, \mathrm{CD}_{13}{ }^{+}, \mathrm{EpCAM}^{+}$and $\mathrm{CD} 44^{+}$in HCCLM3 and Huh7 cells transduced with Gly-tRF mimic using flow cytometry. Interestingly, our results showed that HCCLM3 cells stably transduced with the Gly-tRF mimic had higher percentages of $\mathrm{CD}_{13}{ }^{+}, \mathrm{EpCAM}^{+}$and $\mathrm{CD}_{4} 4^{+}$(Fig. 2A). However, the percentage of CD133 cells showed no significant difference attributable to discrete detection data (Fig. 2A). Similarly, Gly-tRF elevated the percentages of $\mathrm{CD}_{133^{+}}, \mathrm{CD}_{13}{ }^{+}, \mathrm{EpCAM}^{+}$ and CD44 ${ }^{+}$in Huh7 cells (Fig. 2C). This result suggests that Gly-tRF expression may be involved in the regulation of LCSC.

Sphere formation assay is a widely used model for studying CSCs [29]. Next, the effect of Gly-tRF on the sphere formation ability was further investigated. Our study reveals that cells transduced with the GlytRF mimic had a higher LCSC sphere formation ability (Fig. 2B, D). These findings indicate that in human HCC, Gly-tRF plays a role in the maintenance of LCSClike properties.

\section{Gly-tRF intensifies HCC cell migration and EMT}

Convincing evidence shows that the existence of CSCs is responsible for EMT in cancer cells [30]. In addition, a large amount of credible evidence shows the driving role of CSCs in tumour migration [31]. Therefore, we continue to evaluate the effect of Gly-tRF on the migration of HCC cells.

Through Transwell assays, we observed that the number of migrated cells increased after Gly-tRF mimic transduction and decreased after Gly-tRF inhibitor transduction (Fig. 3A, B, E, F) in HCCLM3 and Huh7 cells.

Wound healing assay was used to confirm the effect of Gly-tRF on HCC cell migration. Our results showed that Gly-tRF mimic transduction accelerated wound healing, while Gly-tRF inhibitor transduction slowed wound healing at $48 \mathrm{~h}$, (Fig. 3C, D, G, H). These data suggest that Gly-tRF inhibits migration in HCC.

EMT allows cancer cells to infiltrate into the surrounding tissues and metastasizes [32], cancer cell migration is often accompanied by EMT. Next, we used Western blotting to detect the abundance of key markers of EMT. The results showed that in the cells transduced with the GlytRF inhibitor, the abundance of N-cadherin decreased, while the abundance of E-cadherin increased. It was also observed that Gly-tRF mimic transduction correspondingly reversed this change (Fig. 3I, J). These results demonstrate that Gly-tRF as a cancer-promoter, plays critical roles in HCC by promoting cell migration and EMT. 


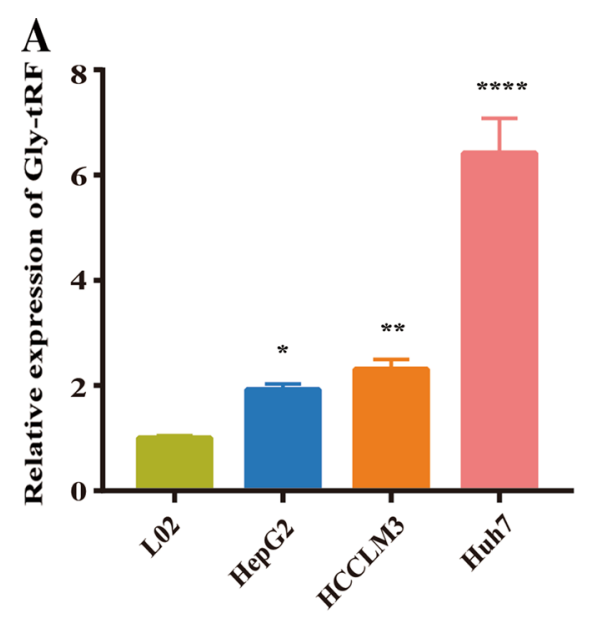

C

\begin{tabular}{cc}
\hline Cancer Type & LIHC \\
\hline Median Expression of Tumor & $\mathbf{7 5 5 . 0 6 0}$ \\
Median Expression of Normal & $\mathbf{6 5 5 . 4 0 0}$ \\
\hline
\end{tabular}
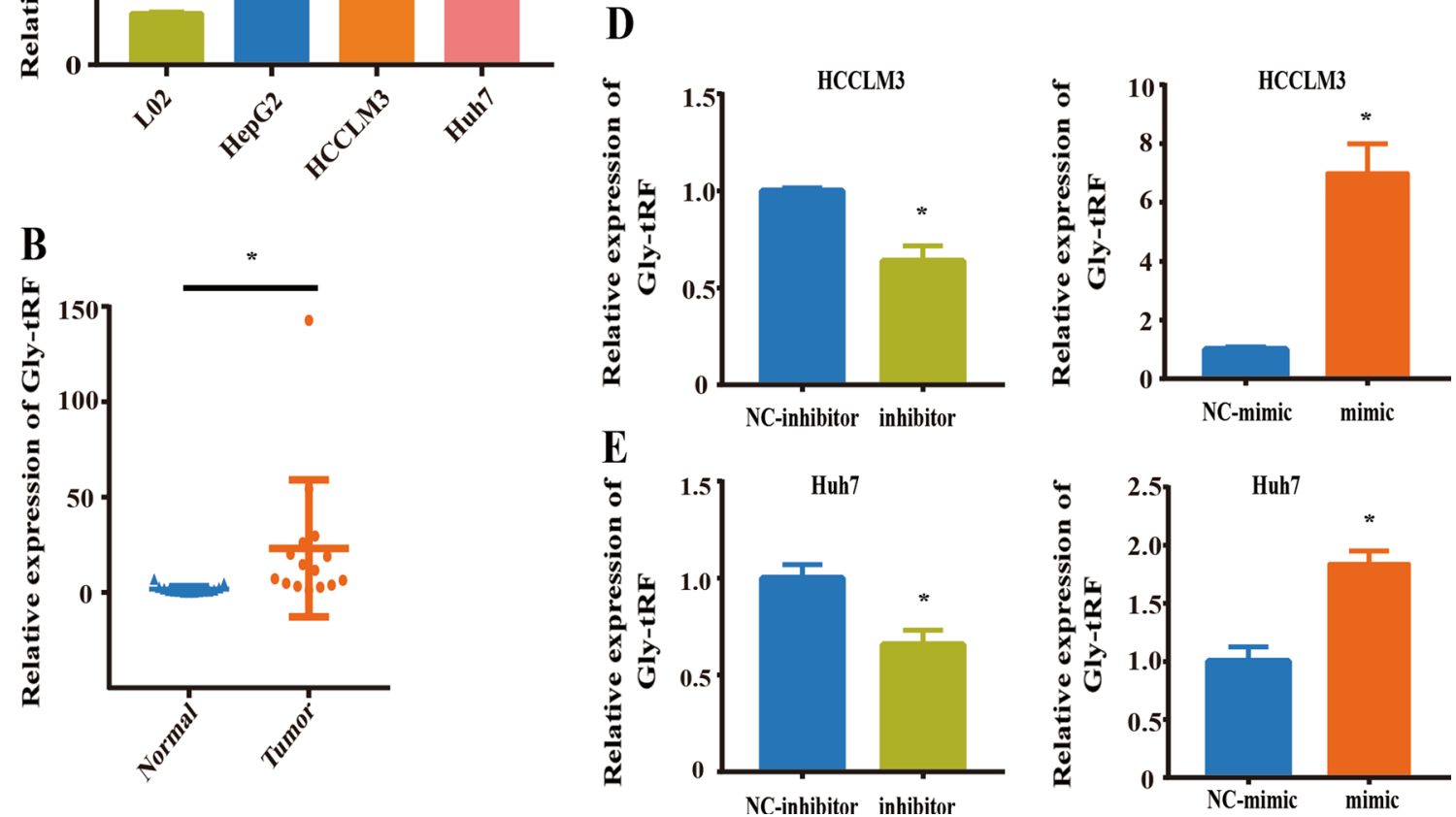

Fig. 1 Gly-tRF expression is elevated in HCC. A Quantitative real-time PCR (qRT-PCR) shows that Gly-tRF is highly expressed in HCC cell lines (HCCLM3, Huh7, HepG2), compared to L02 hepatocytes. B Scatter plots shows that in HCC specimens, the expression of Gly-tRF in tumor tissues is elevated compared with adjacent non-tumour ones $(n=15)$. C Based on the online database OncotRF, the median expression level of Gly-tRF in tumour tissues of HCC patients is higher than that in normal tissues. LIHC: Liver hepatocellular carcinoma. D, E Confirming of Gly-tRF enhancement or reduction transfected with Gly-tRF mimic or Gly-tRF inhibitor by qRT-PCR in HCCLM3 and Huh7 cells. Data are shown as mean \pm SD. *P $<0.05$, ${ }^{* *} \mathrm{P}<0.01,{ }^{* * *} \mathrm{P}<0.0001$

\section{Gly-tRF inhibits NDFIP2 3' UTR-driven luciferase reporter activity}

Studies have shown that tRNA-derived fragments inhibit the biological functions by binding to the mRNA $3^{\prime}$ UTR of the target gene and exerting effect similar to that of miRNAs [33, 34]. The online database miRDB allows the use of user-provided tRNA-derived fragment sequences for custom target prediction [35]. To investigate the regulatory effect of Gly-tRF on downstream genes, we used miRDB to predict several Gly-tRF target genes (Table. 2).

Then, we evaluated the effect of Gly-tRF mimic transduction on the expression of selected predicted target genes by

(See figure on next page.)

Fig. 2 Gly-tRF is involved in the maintenance of LCSC-like properties. A, C Flow cytometric analysis to detect the percentage of representative LCSC surface markers (CD133, CD13, EpCAM, CD44) in HCCLM3 and Huh7 cells stably transfected with Gly-tRF NC-mimic and Gly-tRF mimic. The statistical graph shows result of three independent experiments. B, D Sphere formation assay to reflect the sphere formation ability of those cells with LCSC-like properties in HCCLM3 and Huh7 transfected with Gly-tRF NC-mimic and Gly-tRF mimic. Scale bar = $100 \mu \mathrm{m}$. The statistical graph shows the diameter of spheres in three independent experiments. Data are shown as mean \pm SD. ns means no significance, ${ }^{*} P<0.05,{ }^{* *} P<0.01$, ${ }^{* * *} \mathrm{P}<0.001,{ }^{* * * *} \mathrm{P}<0.0001$ 

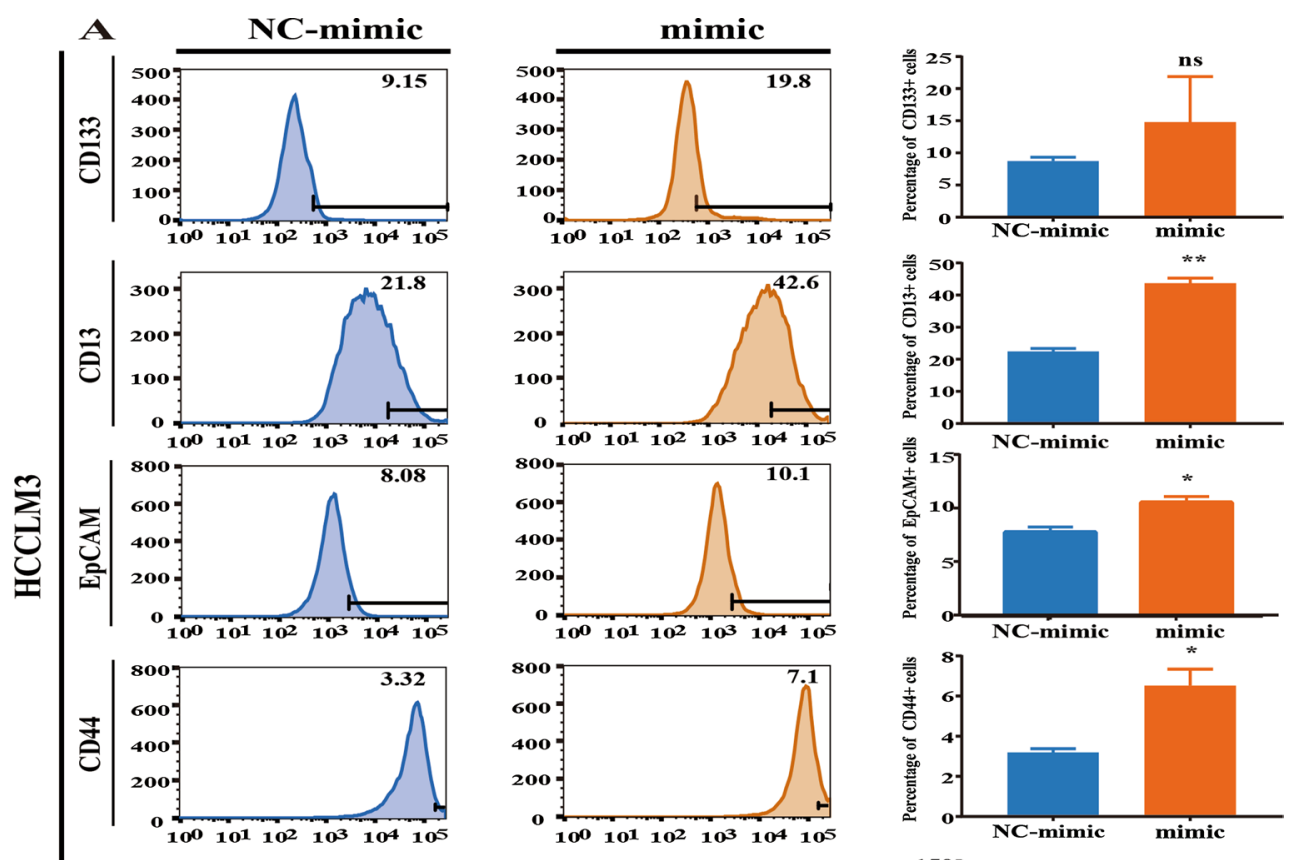

B
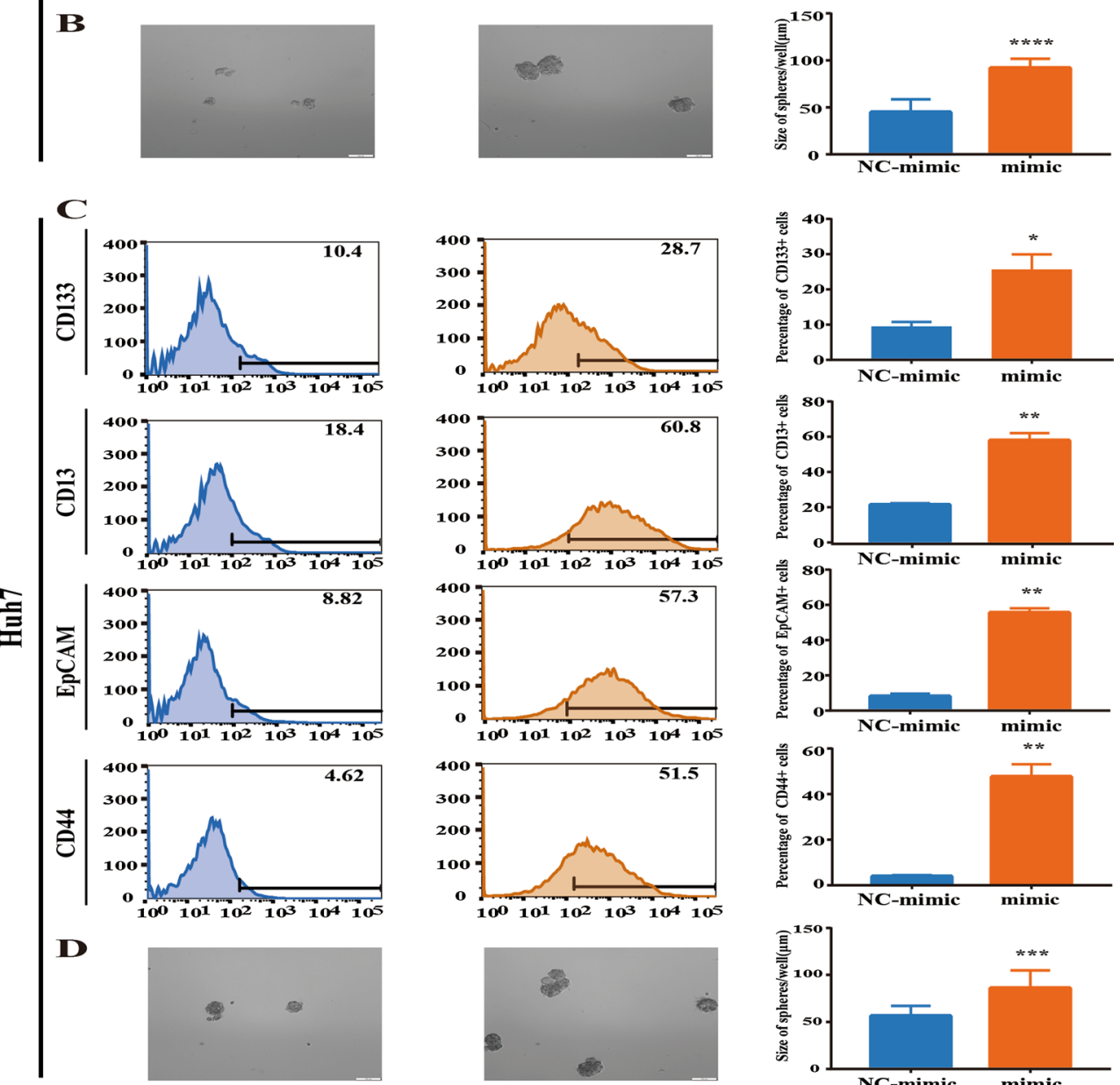

Fig. 2 (See legend on previous page.)

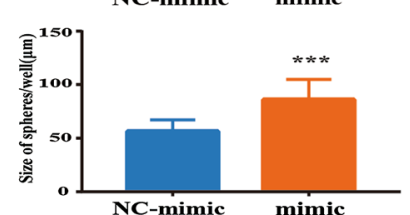



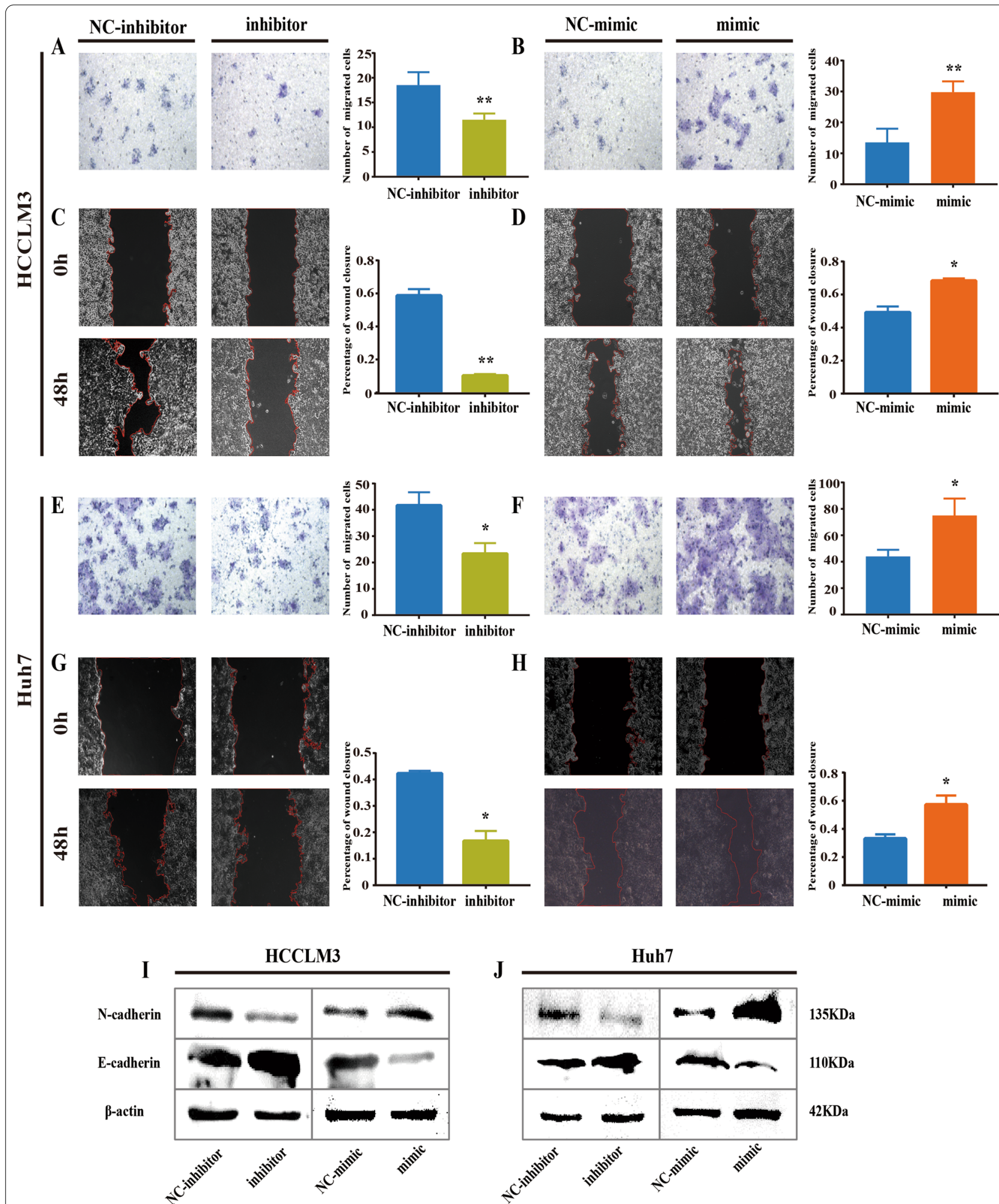

Fig. 3 Gly-tRF intensifies migration and EMT of HCC cells. A, B, E, F Transwell assay performed to evaluate cell migration in HCCLM3 and Huh7 cells after Gly-tRF mimic or Gly-tRF inhibitor transduction. The statistical graph shows the average number of migrated cells in 5 random fields. Magnification, $200 \times$. C, D, G, H Wound healing assay was used to confirm the effect of Gly-tRF on HCC cells migration. The percentage of wound closure represents the effect of Gly-tRF on the migration ability of cancer cells. Magnification, $100 \times$. Data are shown as mean \pm SD of three independent experiments. ns means no significance, ${ }^{*} \mathrm{P}<0.05$, ${ }^{*} \mathrm{P}<0.01 . \mathbf{I}, \mathbf{J}$ Western blotting was performed to detect the abundance of core markers (N-cadherin, E-cadherin) in EMT 
Table 2 The top 8 Gly-tRF target genes predicted by miRDB

\begin{tabular}{|c|c|c|c|c|}
\hline Gene & Gene description & Predicted target score & 3'UTR length & Seed position \\
\hline $\mathrm{ABHD} 17 \mathrm{~B}$ & Abhydrolase domain containing 17B & 96 & 129 & 82 \\
\hline NDFIP2 & Nedd4 family interacting protein 2 & 96 & 3564 & 32 \\
\hline KCNK10 & $\begin{array}{l}\text { Potassium two pore domain channel Subfamily K } \\
\text { member } 10\end{array}$ & 95 & 5427 & 676 \\
\hline RNF103 & Ring finger protein 103 & 95 & 1564 & 896 \\
\hline $\begin{array}{l}\text { CXXC4 } \\
\text { OXTR }\end{array}$ & $\begin{array}{l}\text { CXXC finger protein } 4 \\
\text { Oxytocin receptor }\end{array}$ & $\begin{array}{l}95 \\
95\end{array}$ & $\begin{array}{l}4106 \\
2569\end{array}$ & $\begin{array}{l}2120,2783 \\
1560,2131,2537\end{array}$ \\
\hline WDR44 & WD repeat domain 44 & 94 & 974 & 860 \\
\hline OSER1 & Oxidative stress responsive serine rich 1 & 94 & 1113 & 29 \\
\hline
\end{tabular}

qRT-PCR. Nedd4 family interacting protein 2(NDFIP2) is an activator of Nedd4 family E3 ubiquitin ligases [36], and its mRNA level decreased after Gly-tRF mimic transduction (Fig. 4A). Interestingly, the NDFIP2 level was found to be significantly reduced in $371 \mathrm{HCC}$ tissue, compared with 50 normal liver tissues by matching the expression levels of NDFIP2 in the TCGA database (https://portal.gdc.cancer. gov/), and low NDFIP2 expression was found to imply a poor prognosis of $\mathrm{HCC}$ based on the Kaplan-Meier Plotter database (http://kmplot.com/) (Fig. 4B, C). Immunohistochemistry was used to verify the expression of NDFIP2 in $\mathrm{HCC}$, and the results showed that 58/84 (69\%) of the samples had lower NDFIP2 expression in tumour tissues than in non-tumor tissues (Fig. 4D). These evidences support our preliminary prediction that Gly-tRF may target to regulate NDFIP2 in HCC.

Dual luciferase reporter assays were employed to determine whether Gly-tRF binds to the seed sequence in the NDFIP2 3' UTR. There were potential targeted binding sites of Gly-tRF on NDFIP2 3' UTR based on the miRDB database (Fig. 4E). Our results showed that luciferase activity was significantly reduced when HEK-293T cells were co-transduced with Gly-tRF mimic and NDFIP2 wt reporter plasmid (Fig. 4F). However, pGL6 empty vector and NDFIP2 mut reporter plasmid did not inhibit luciferase activity (Fig. 4F).

We detected the effect of Gly-tRF mimic transduction on the protein expression level of NDFIP2 by immunofluorescence and Western blotting analyses. When cells were transduced with the Gly-tRF mimic, the protein expression level of NDFIP2 was decreased (Fig. 5A-C). Our experiments demonstrate that Gly-tRF specifically targets NDFIP2 in HCC.

\section{Overexpression of NDFIP2 partially reverses the HCC-promoting effect of Gly-tRF}

Next, we further investigated whether overexpression of NDFIP2 abolishes or reverses the promotive effect of Gly-tRF on the migration of HCC cells and LCSC-like properties. We constructed the NDFIP2 overexpression plasmid, and when the NDFIP2 overexpression plasmid was transfected into HCCLM3 cells, the expression levels of NDFIP2 mRNA and protein were verified to be increased through qRT-PCR and Western blotting analyses (Additional file 2: Fig. S2A, B). Our results showed that overexpression of NDFIP2 reliably reversed the increase in LCSC sphere formation ability induced by Gly-tRF in HCCLM3 cells (Fig. 6A, B). Co-transfection of the NDFIP2 overexpression plasmid with the GlytRF mimic abolished Gly-tRF-induced cell migration and EMT-related marker abundance in HCCLM3 cells (Fig. 6C-G). Collectively, these functional reversal experiments further confirmed that Gly-tRF acts as a cancerpromotor by targeting NDFIP2.

\section{Gly-tRF/NDFIP2 functions by activating the AKT signalling pathway}

Next, we aimed to identify the signalling pathways through which Gly-tRF/NDFIP2 functions. Through GO molecular function (GO-MF) analysis, we found that Gly-tRF/

\footnotetext{
(See figure on next page.)

Fig. 4 Gly-tRF inhibits NDFIP2 3' UTR luciferase reporter activity. A qRT-PCR was used to detect the mRNA expression of target genes predicted by miRDB in HCCLM3 cells transfected with Gly-tRF mimic. B Expression of NDFIP2 gene in 371 HCC tissues and 50 normal liver tissues from the TCGA database. CThe expression of NDFIP2 is related to the prognosis of HCC Kaplan-Meier Plotter database. D The expression of NDFIP2 in HCC was verified by immunohistochemistry. E The sequence of Gly-tRF and the binding site of NDFIP2 3'UTR are shown. The sequence of the NDFIP2 mutant plasmid is also listed. $\mathbf{F}$ Luciferase activity of cells transfected with pGL6 empty vector(vector), NDFIP2 $3^{\prime}$ UTR wild-type(wt) and mutant plasmids(mut) co-transfected with Gly-tRF NC-mimic and Gly-tRF mimic in HEK-293T cells. Renilla luciferase activity (R value) was performed to correct and standardize firefly fluorescence activity ( $F$ value). Statistical graph data is expressed by F/R of three independent experiments. F Western blotting performed to detect the level of NDFIP2 protein in HCC cells stably transfected with Gly-tRF NC-mimic and Gly-tRF mimic. ${ }^{*} P<0.05$, ${ }^{* *} \mathrm{P}<0.01,{ }^{* * * *} \mathrm{P}<0.0001$
} 

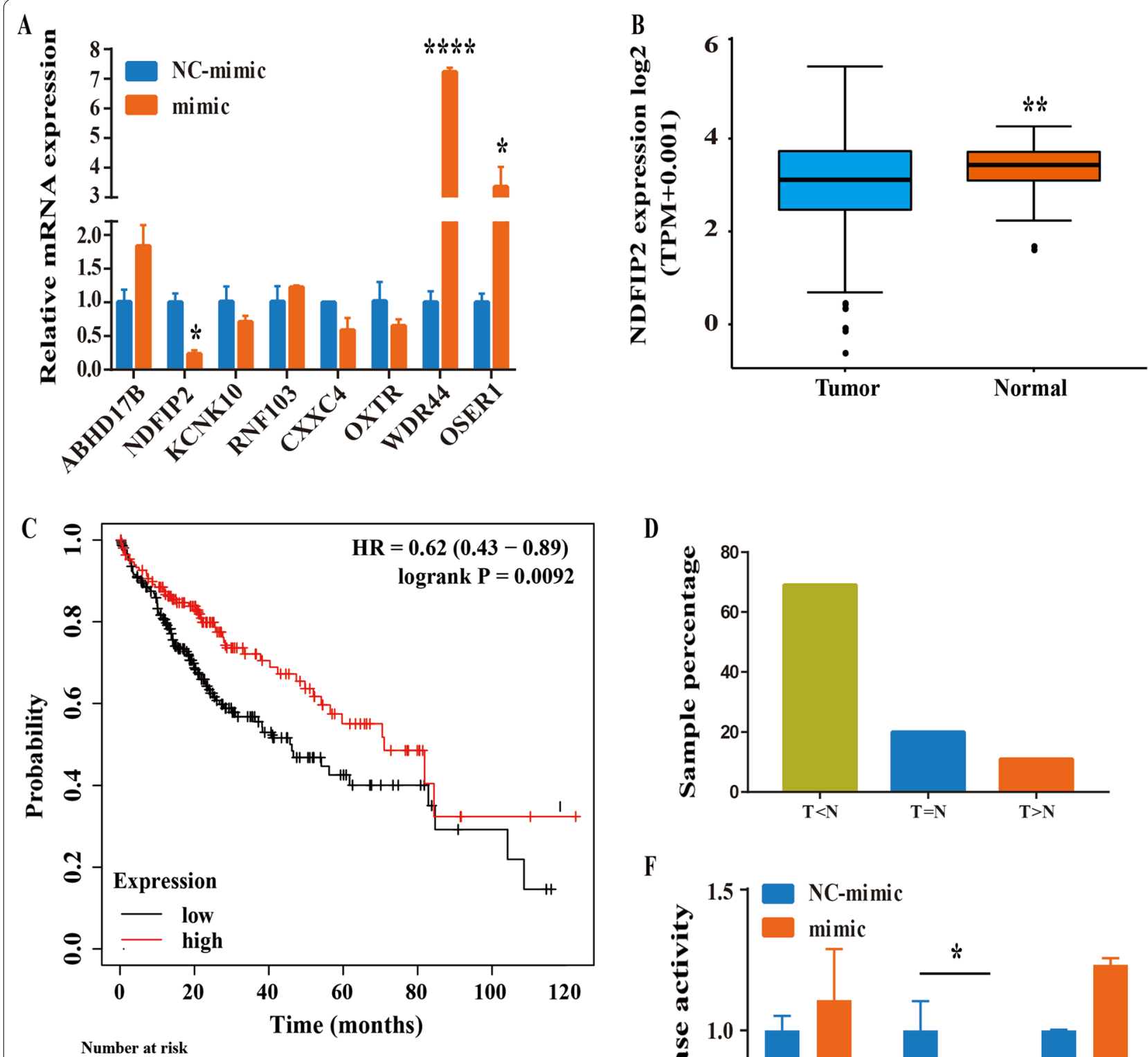

D

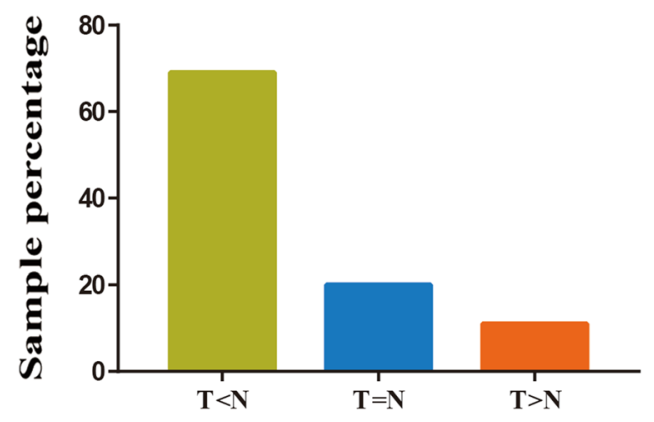

$\begin{array}{rrrrrrrr}\text { low } & 211 & 90 & 41 & 19 & 10 & 4 & 0 \\ \text { high } & 153 & 92 & 43 & 23 & 9 & 2 & 1\end{array}$

E

Gly-tRF

NDFIP2 3' UTR (wt)

3' aagauggugacuugg UGGUUACg 5'

NDFIP2 3' UTR (mut) $\quad 5^{\prime}$ cecgacattcettttcca GATCATCt 3'

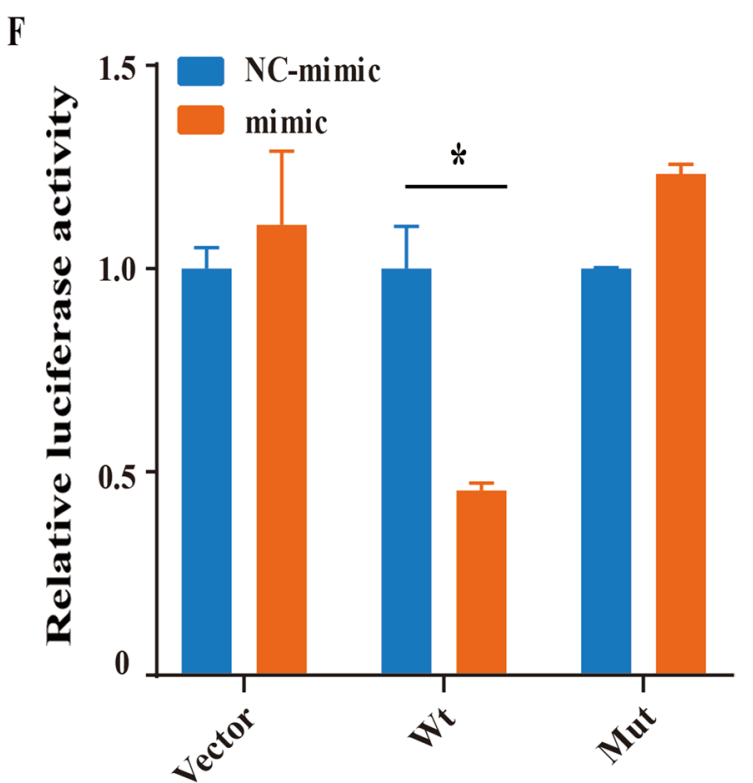

Fig. 4 (See legend on previous page.) 

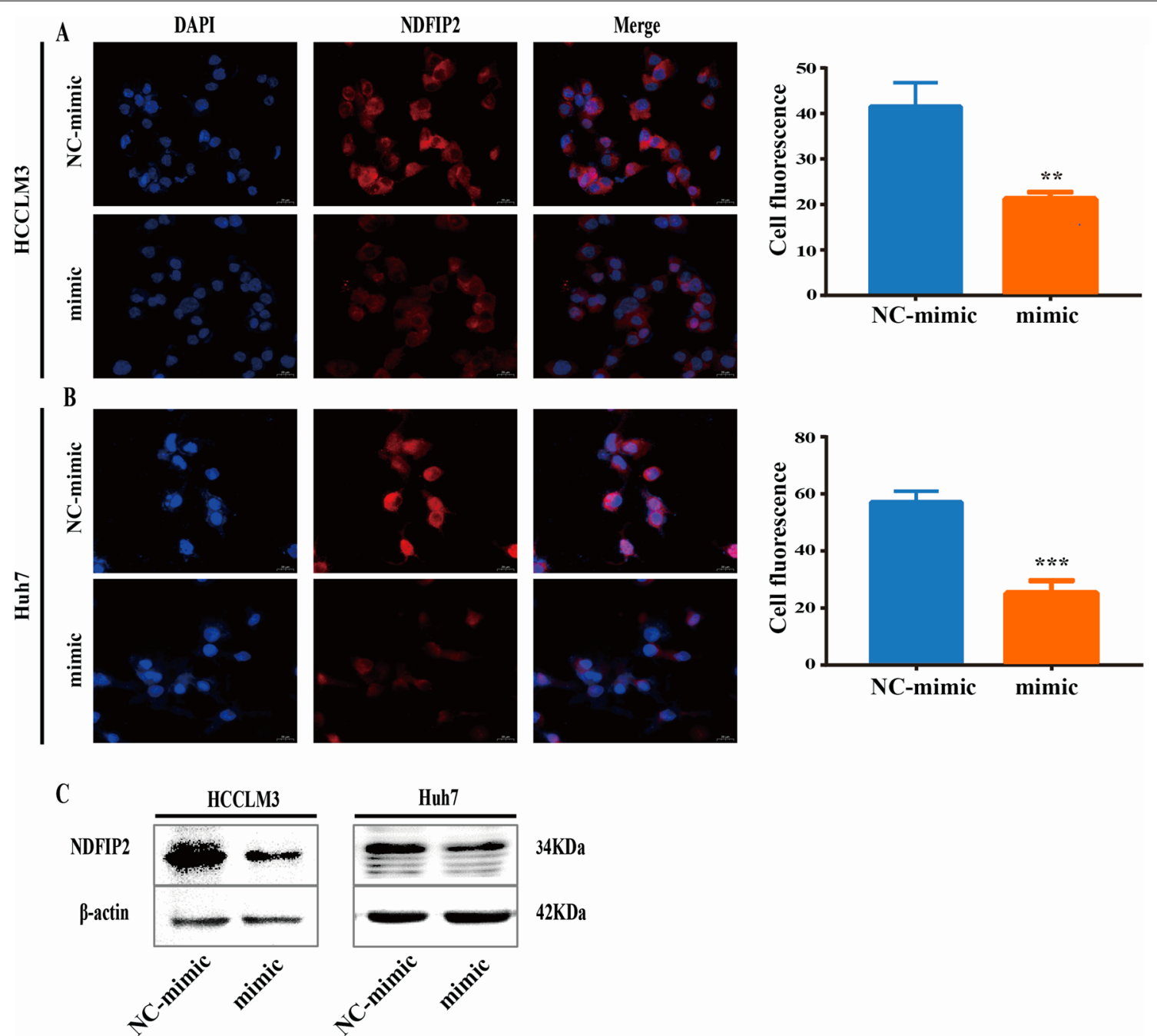

$34 \mathrm{KDa}$

$42 \mathrm{KDa}$

Fig. 5 Gly-tRF inhibits the expression level of NDFIP2 protein. A-C Immunofluorescence and Western blotting were performed to detect the level of NDFIP2 protein in HCC cells stably transfected with Gly-tRF NC-mimic and Gly-tRF mimic. The statistical graph shows the average value of cell fluorescence in 3 random fields. Magnification, $400 \times$. Data are shown as mean $\pm S D$. ${ }^{* *} P<0.01,{ }^{* *} \mathrm{P}<0.001$

NDFIP2 is mainly involved in ubiquitin protein ligase activity and phosphatidylinositol 3-kinase (PI3K) activity (Fig. 7A).

Previous studies have shown that depletion of NDFIP2 can inhibit AKT activation, and promote HeLa cell proliferation [37]. Western blotting was used to investigate whether the AKT signalling pathway is involved in the function of NDFIP2. We found that in
Gly-tRF mimic transduced HCCLM3 cells, the abundance of phosphorylated AKT was increased and was reversed by overexpression of NDFIP2 (Fig. 7B).

In summary, the above data indicate that Gly-tRF negatively regulates the expression of NDFIP2, thereby activating the AKT signalling pathway to promote HCC (Fig. 7C).

\section{(See figure on next page.)}

Fig. 6 Overexpression of NDFIP2 partially reverses the HCC-promoting effect of Gly-tRF. A, B The sphere formation assay was performed to verify that the overexpression of NDFIP2 reversed CSCs sphere formation ability caused by Gly-tRF. Magnification, $100 \times$. C-D. The Transwell assay was performed to verify that the overexpression of NDFIP2 reversed the promotion of Gly-tRF on HCC cell migration. Magnification, $200 \times$. E, F Wound healing assay was performed to verify that the overexpression of NDFIP2 reversed the promotion of Gly-tRF on HCC cell migration. Magnification, $100 \times$. G Western blotting was performed to detect the abundance of core markers (N-cadherin, E-cadherin) in EMT. Data are shown as mean \pm SD. ${ }^{*} \mathrm{P}<0.05,{ }^{* * P}<0.01,{ }^{* * *} \mathrm{P}<0.0001$ 


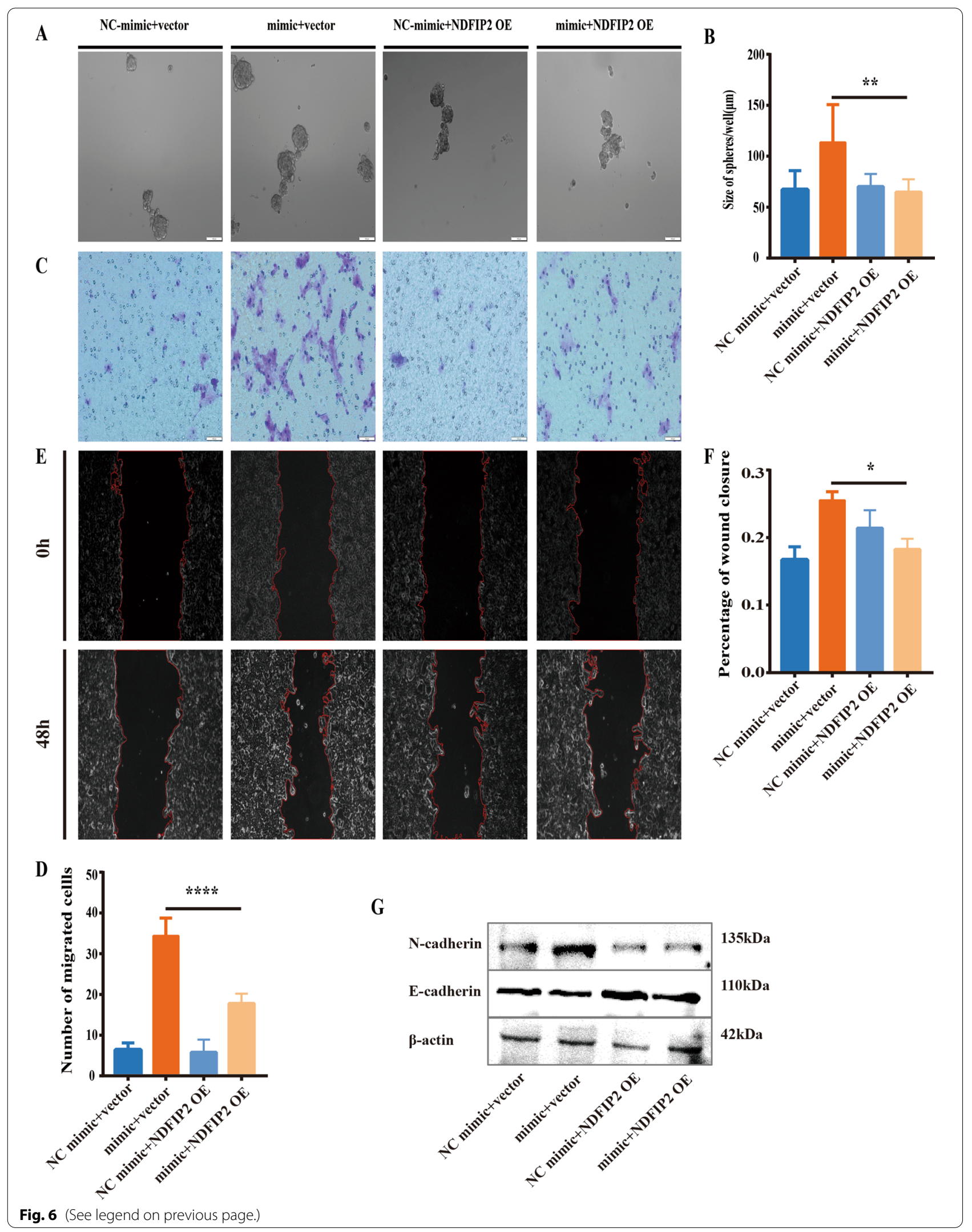


A

ubiquitin-like protein transferase activity ubiquitin-protein transferase activity Ras GTPase binding small GTPase binding protein serine/threonine kinase activity ubiquitin protein ligase activity ubiquitin protein ligase activity RNA polymerase II transcription factor binding phosphatase binding hormone receptor binding phosphatidylinositol phosphate binding nuclear localization sequence binding signal sequence binding Ran GTPase binding 1-phosphatidylinositol-3-kinase activity phosphatidylinositol 3-kinase activity phosphatidylinositol phosphate kinase activity phosphatidylinositol 3-kinase activity nuclear import signal receptor activity receptor signaling complex scaffold activity

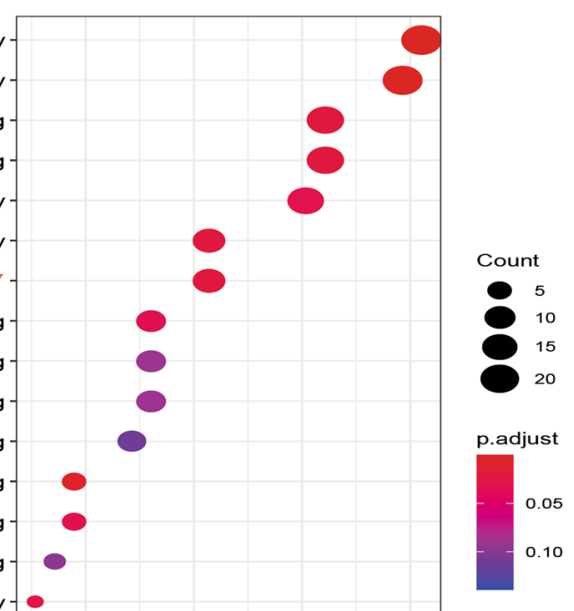

B AKT

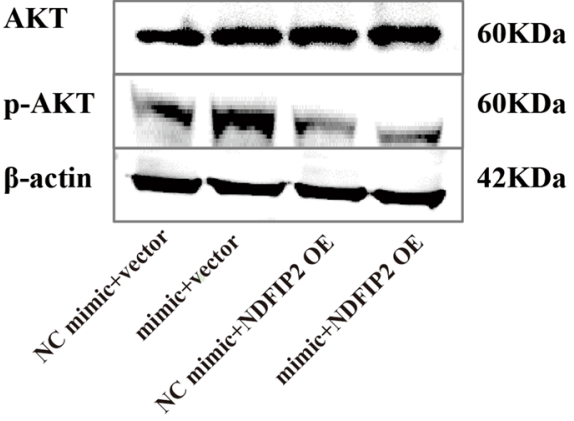

C

Migration

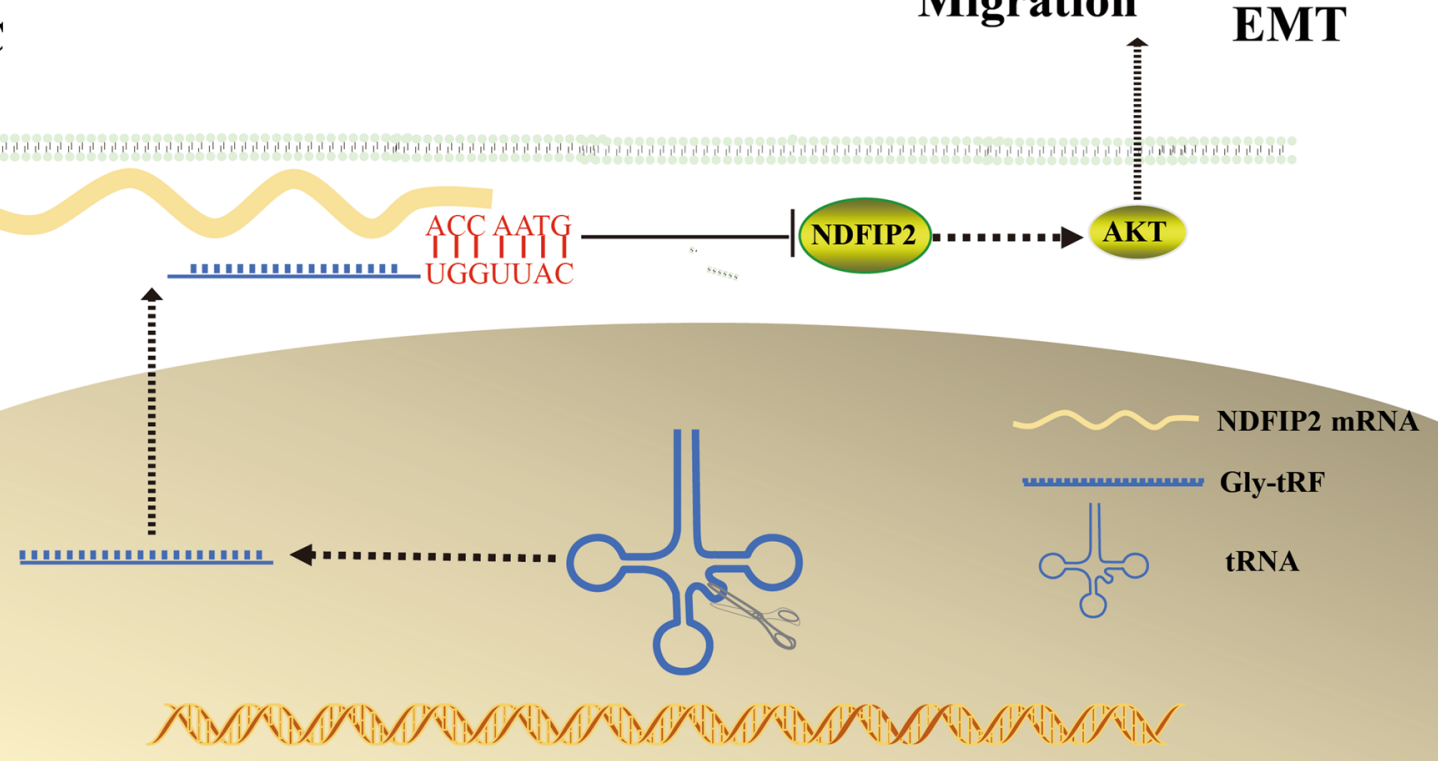

Fig. 7 Gly-tRF/NDFIP2 functions through activating the AKT signalling pathway. A GO molecular function (GO-MF) analysis of NDFIP2 gene. B Western blotting was performed to detect the phosphorylated levels of AKT. C Model diagram of Gly-tRF/NDFIP2 axis functioning in HCC 


\section{Discussion}

The idea that transfer RNA derived fragments (tRFs and tiRNAs) play key roles in mechanisms of tumorigenesis and tumour development is supported by accumulating research evidence. However, the effect of tRFs and tiRNAs on HCC is still unknown, and further research is needed. In this regard, current research has identified a tRNA derived fragment, Gly-tRF, that is upregulated in $\mathrm{HCC}$ cell lines and HCC tissues. Furthermore, our results confirm that elevated Gly-tRF promotes HCC cell migration These results support the important roles of Gly-tRF in the mechanism of HCC, which is of great significance for the development of new research focuses on strategies for the diagnosis and treatment of HCC.

Previous studies have shown the biological function and potential molecular mechanism of dysregulated functional tRFs and tiRNAs in HCC. Deep-sequencing analysis of small RNAs identified a tRF named tRF_U3_1, that exhibits increased abundance in the Huh7 cell line and negatively regulates viral gene expression [38]. Highthroughput sequencing results of small RNAs in liver tissues of patients with advanced hepatitis B or C and HCC showed that $t R F s$ and tiRNAs have the highest abundance in chronically infected liver tissue, and that their abundance is changed in HCC [39]. Accumulating evidence reveals the potential relationship between tRFs and HCC. Although the tRNA-derived fragment subtypes and tumour types were different from those studied previously, those of previous studies indicate that elevated levels of tRNA-derived fragments act as a cancer-promoting factor [40-42]. However, the expression levels of tRFs are affected by the cellular context, and the transcription characteristics of tRFs are related to personal attributes [43]. These variations make discovering the function of tRFs extremely complicated. Currently, tRFs represent an emerging, elusive, challenging and promising field, and their regulation of biological activities requires more indepth evaluation and more convincing evidence.

tRF usually targets mRNA $3^{\prime}$ UTR through miRNA-like effects and plays potential roles in post-transcriptional regulation [44]. The $t R F / m i R-1280$ derived from $t R N A^{\text {Leu }}$ and pre-miRNA inhibits Notch signaling pathway by directly targeting Notch ligand JAG2 mRNA 3' UTR, inhibiting the growth and metastasis of colorectal cancer cells [18]. tRF-17-79MP9PP targets THBS1 3' UTR to attenuate breast cancer cell invasion and migration [45]. In this study, we confirmed that NDFIP2 is the direct target of Gly-tRF. We also found that the promotive effects of Gly-tRF on HCC can be reduced by NDFIP2 overexpression.

There have been discussions about the role of tRNAderived fragments in stemness regulation. In mouse stem cell models, $5^{\prime}$ tRNA accumulation has been found to regulate the undifferentiated stem cell status in tumours through differential translation of proteins that regulate cell migration, adhesion, and stress response [46]. PUS7mediated pseudouridylation activates tRF biogenesis to control protein synthesis and stem cell fate determination, and this post-transcriptional regulatory network directly affects tumorigenesis [47]. The results of the present study indicate that Gly-tRF increases the expression of markers indicating a stem cell-like phenotype and promotes LCSC-like properties. Collectively, the above findings and our results suggest that it is meaningful to integrate the study of tRNA-derived fragments into research on cancer stem cells.

The potential mechanism by which tRNA-derived fragments control the biological processes of HCC cells is multi-step and complex. Importantly, we found that the tumour -promoting effect of Gly-tRF on HCC cells depends on the AKT signalling pathway. Overexpression of NDFIP2 weakened the tumour-promoting effect of Gly-tRF on HCC cells and restored the level of phosphorylated AKT. Accumulating evidence also indicates the activation of the AKT signalling pathway in $\mathrm{HCC}$ biogenesis $[48,49]$. NDFIP2 regulates the stability of its target proteins by activating E3 ubiquitin ligases [36]. Our GO-MF analysis result also implied that NDFIP2 is involved in ubiquitin mediated proteolysis. We thus speculate that NDFIP2 regulates the AKT signalling pathway through the ubiquitination of downstream target proteins. However, our current research has not verified this speculation. Additionally, the number of human tRFs identified to date exceeds the number of human protein-coding genes, the mechanism of tRFs involved in biogenesis has not yet been elucidated, and multiple mechanisms may be responsible [43].

\section{Conclusion}

Gly-tRF regulates the migration of HCC cells and LCSClike properties through negative regulation of NDFIP2 and activation of the AKT signalling pathway. This result may provide a theoretical basis for Gly-tRF as a target in future treatment of HCC. However, the small number of clinical samples and the limitations of detection methods may affect the true expression of Gly-tRF. The expression abundance of $\mathrm{tRF}$ is affected by the cell environment, and the transcription characteristics are also related to personal attributes, the dynamic changes of tRF involved in disease progression need further study.

\section{Abbreviations}

tRNA: Transfer RNA; Gly-tRF: Glycine tRNA-derived fragments; HCC: Hepatocellular carcinoma; CSCs: Cancer stem cells; LCSCs: Liver cancer stem cells; NDFIP2: Nedd4 family interacting protein 2; EpCAM: Epithelial cell adhesion molecule; tRFs: TRNA-derived small RNA fragments; tiRNAs: TRNA-derived 
stress-induced RNA; ncRNAs: Non-coding RNAs; AFLD: Alcoholic fatty liver disease; CCTCC: China Center for Type Culture Collection; STR: Short tandem repeats; DMEM: Dulbecco's modified Eagle's medium; FBS: Fetal bovine serum; PBS: Phosphate belanced solution; qRT-PCR: Quantitative real-time polymerase chain reaction; PE: Phycoerythrin; APC: Allophycocyanin; Opti-MEM: Optimized minimum essential medium; DAPI: 4',6-Diamidino-2-phenylindole; TCGA: The Cancer Genome Atlas; DEGs: Differentially expressed genes; GO: Gene Ontology; ANOVA: Analysis of Variance; NC: Negative control; 3' UTR: 3'-Untranslated regions; GO-MF: GO molecular function; AKT: Protein Kinase B: JNK: C-Jun N-terminal kinase; PUS7: Pseudouridine synthase 7.

\section{Supplementary Information}

The online version contains supplementary material available at https://doi. org/10.1186/s12935-021-02102-8.

\section{Additional file 1: Figure S1. A flowchart of the article to show the} research methodology.

Additional file 2: Figure S2. A-B. Real time PCR (A) and western blotting (B) were used to detect the level of NDFIP2 mRNA and NDFIP2 protein when Gly-tRF NC-mimic and Gly-tRF mimic co-transfected with NDFIP2 overexpression plasmid in HCCLM3 cells. Data are shown as mean \pm SD. ${ }^{* * P}<0.01,{ }^{* * * P}<0.0001$

\section{Acknowledgements}

We would like to thank the other members of this laboratory for their help and support. Thanks to the School of Life Sciences, Lanzhou University for the convenience of using experimental equipment.

\section{Authors' contributions}

$\mathrm{XL}, \mathrm{YZ}$ and $\mathrm{JH}$ : Experiment conception and implementation. $\mathrm{YZ}, \mathrm{JH}$ and $\mathrm{LL}$ : Data analysis. YZ and LL: Draft manuscript. JH, MY, QZ, XS: Technical guidance, experimental suggestions and specimen collection. YL, YW, ZF and DZ: Academic contributions and manuscript revision. LH and YC: Flow cytometry implementation. XL: Fund support. All authors read and approved the final manuscript.

\section{Funding}

This work was supported by the National Natural Science Foundation of China (Grant Number 82060119), and Gansu Province Science and Technology Planning Project (Grant Number 18JR2TA018), and Major Science and Technology Project of Gansu Province (Grant Number 1602FKDA001), and Gansu Province Health Industry Scientific Research Project (Grant Number GSWSKY-2015-49).

\section{Availability of data and materials}

All data supporting this research are included in the article and supplementary materials.

\section{Declarations}

\section{Ethics approval and consent to participant.}

The study was approved by the hospital ethics committee and according to the institutional review committee's procedures, all patients had signed an informed consent form before the study.

\section{Consent for publication}

All authors read and approved the final manuscript.

\section{Competing interests}

All authors declare no conflicts of competing interest in this paper.

\section{Author details}

${ }^{1}$ The First Clinical Medical College of Lanzhou University, Lanzhou University, 222 Tianshui South Road, Lanzhou 730000, China. ${ }^{2}$ Department of General Surgery, The First Hospital of Lanzhou University, Lanzhou 730000, China. ${ }^{3}$ Gansu Province Key Laboratory of Biotherapy and Regenerative Medicine, Lanzhou 730000, China. ${ }^{4}$ School of Life Science of Lanzhou University, Lanzhou University, Lanzhou 730000, China.
Received: 3 March 2021 Accepted: 19 July 2021

Published online: 18 September 2021

\section{References}

1. Llovet JM, Kelley RK, Villanueva A, Singal AG, Pikarsky E, Roayaie S, Lencioni R, Koike K, Zucman-Rossi J, Finn RS. Hepatocellular carcinoma. Nat Rev Dis Primers. 2021;7(1):6.

2. Kulik L, El-Serag HB. Epidemiology and management of hepatocellular carcinoma. Gastroenterology 2019;156(2):477-491 e471.

3. Krishnan MS, Rajan KdA, Park J, Arjunan V, Garcia Marques FJ, Bermudez A, Girvan OA, Hoang NS, Yin J, Nguyen MH, et al. Genomic analysis of vascular invasion in hepatocellular carcinoma (HCC) reveals molecular drivers and predictive biomarkers. Hepatology. 2020;73(6):2342-60.

4. Sun C, Fu Z, Wang S, Li J, Li Y, Zhang Y, Yang F, Chu J, Wu H, Huang X, et al. Roles of tRNA-derived fragments in human cancers. Cancer Lett. 2018:414:16-25.

5. Park J, Ahn SH, Shin MG, Kim HK, Chang S. tRNA-derived small RNAs: novel epigenetic regulators. Cancers (Basel). 2020;12(10):2773.

6. Shen Y, Yu X, Zhu L, Li T, Yan Z, Guo J. Transfer RNA-derived fragments and tRNA halves: biogenesis, biological functions and their roles in diseases. J Mol Med (Berl). 2018;96(11):1167-76.

7. Godoy PM, Bhakta NR, Barczak AJ, Cakmak H, Fisher S, MacKenzie TC, Patel T, Price RW, Smith JF, Woodruff PG, et al. Large differences in small RNA composition between human biofluids. Cell Rep. 2018;25(5):1346-58.

8. Chiou NT, Kageyama R, Ansel KM: Selective export into extracellular vesicles and function of tRNA fragments during $T$ cell activation. Cell Rep 2018, 25(12):3356-3370 e3354.

9. Li F, Kaczor-Urbanowicz KE, Sun J, Majem B, Lo HC, Kim Y, Koyano K, Rao SL, Kang SY, Kim SM, et al. Characterization of human salivary extracellular RNA by next-generation sequencing. Clin Chem. 2018;64(7):1085-95.

10. Molla-Herman A, Angelova MT, Ginestet M, Carre C, Antoniewski C, Huynh JR. tRNA fragments populations analysis in mutants affecting tRNAs processing and tRNA methylation. Front Genet. 2020;11:518949.

11. Jia Y, Tan W, Zhou Y. Transfer RNA-derived small RNAs: potential applications as novel biomarkers for disease diagnosis and prognosis. Ann Transl Med. 2020;8(17):1092

12. Goodarzi H, Liu X, Nguyen HC, Zhang S, Fish L, Tavazoie SF. Endogenous tRNA-derived fragments suppress breast cancer progression via YBX1 displacement. Cell. 2015;161(4):790-802.

13. Cui Y, Huang Y, Wu X, Zheng M, Xia Y, Fu Z, Ge H, Wang S, Xie H. Hypoxia-induced tRNA-derived fragments, novel regulatory factor for doxorubicin resistance in triple-negative breast cancer. J Cell Physiol. 2019;234(6):8740-51.

14. Telonis AG, Rigoutsos I. Race disparities in the contribution of miRNA isoforms and tRNA-derived fragments to triple-negative breast cancer. Cancer Res. 2018;78(5):1140-54.

15. Sun C, Yang F, Zhang Y, Chu J, Wang J, Wang Y, Zhang Y, Li J, Li Y, Fan R, et al. tRNA-derived fragments as novel predictive biomarkers for trastuzumab-resistant breast cancer. Cell Physiol Biochem. 2018;49(2):419-31.

16. Martens-Uzunova E, Jalava S, Dits N. Leenders Gv: Diagnostic and prognostic signatures from the small non-coding RNA transcriptome in prostate cancer. Oncogene. 2012;31(8):978-91.

17. Olvedy M, Scaravilli M, Hoogstrate Y, Visakorpi T. A comprehensive repertoire of tRNA-derived fragments in prostate cancer. Oncotarget. 2016;7(17):24766-77.

18. Huang B, Yang H, Cheng X, Wang D, Fu S, Shen W, Zhang Q, Zhang L, Xue Z, Li Y, et al. tRF/miR-1280 suppresses stem cell-like cells and metastasis in colorectal cancer. Can Res. 2017;77(12):3194-206.

19. Li S, Shi X, Chen M, Xu N, Sun D, Bai R, Chen H, Ding K, Sheng J, Xu Z. Angiogenin promotes colorectal cancer metastasis via tiRNA production. Int J Cancer. 2019;145(5):1395-407.

20. Yu M, Lu B, Zhang J, Ding J, Liu P, Lu Y. tRNA-derived RNA fragments in cancer: current status and future perspectives. J Hematol Oncol. 2020;13(1):121

21. Zhong F, Hu Z, Jiang K, Lei B, Wu Z. Complement C3 activation regulates the production of tRNA-derived fragments Gly-tRFs and promotes alcohol-induced liver injury and steatosis. Cell Res. 2019;29(7):548-61. 
22. Lakshman R, Shah R, Reyes-Gordillo K, Varatharajalu R. Synergy between NAFLD and AFLD and potential biomarkers. Clin Res Hepatol Gastroenterol. 2015;39(Suppl 1):S29-34.

23. Da Z, Gao L, Su G, Yao J, Fu W, Zhang J, Zhang X, Pei Z, Yue P, Bai B, et al. Bioinformatics combined with quantitative proteomics analyses and identification of potential biomarkers in cholangiocarcinoma. Cancer Cell Int. 2020:20:130

24. Green JA, Ansari MY, Ball HC, Haqqi TM. tRNA-derived fragments (tRFs) regulate post-transcriptional gene expression via AGO-dependent mechanism in IL-1 beta stimulated chondrocytes. Osteoarthritis Cartilage. 2020;28(8):1102-10.

25. Zhuo Z, Hu J, Yang X, Chen M, Lei X, Deng L, Yao N, Peng Q, Chen Z, Ye W, et al. Ailanthone inhibits Huh7 cancer cell growth via cell cycle arrest and apoptosis in vitro and in vivo. Sci Rep. 2015:5:16185.

26. Yao D, Sun X, Zhou L, Amanullah M, Pan X, Liu Y, Liang M, Liu P, Lu Y. OncotRF: an online resource for exploration of tRNA-derived fragments in human cancers. RNA Biol. 2020;17(8):1081-91.

27. Chai $S$, Ng KY, Tong M, Lau EY, Lee TK, Chan KW, Yuan YF, Cheung TT, Cheung ST, Wang XQ, et al. Octamer 4/microRNA-1246 signaling axis drives Wnt/beta-catenin activation in liver cancer stem cells. Hepatology. 2016;64(6):2062-76.

28. Wu J, Zhu P, Lu T, Du Y, Wang Y, He L, Ye B, Liu B, Yang L, Wang J, et al. The long non-coding RNA LncHDAC2 drives the self-renewal of liver cancer stem cells via activation of Hedgehog signaling. J Hepatol. 2019;70(5):918-29.

29. Tian W, Li J, Wang Z, Zhang T, Han Y, Liu Y, Chu W, Liu Y, Yang B. HYD-PEP06 suppresses hepatocellular carcinoma metastasis, epithelial-mesenchymal transition and cancer stem cell-like properties by inhibiting PI3K AKT and WNT/beta-catenin signaling activation. Acta Pharm Sin B. 2021;11(6):1592-606.

30. Zhou Q, Jin P, Liu J, Li S, Liu W, Xi S. HER2 overexpression triggers the IL-8 to promote arsenic-induced EMT and stem cell-like phenotypes in human bladder epithelial cells. Ecotoxicol Environ Saf. 2021;208:111693.

31. Steinbichler TB, Savic D, Dudas J, Kvitsaridze I, Skvortsov S, Riechelmann $\mathrm{H}$, Skvortsova II. Cancer stem cells and their unique role in metastatic spread. Semin Cancer Biol. 2020;60:148-56.

32. Yang J, Antin P, Berx G, Blanpain C, Brabletz T, Bronner M, Campbell K, Cano A, Casanova J, Christofori G, et al. Guidelines and definitions for research on epithelial-mesenchymal transition. Nat Rev Mol Cell Biol. 2020;21(6):341-52.

33. Zhang S, Li H, Zheng L, Li H, Feng C. Identification of functional tRNAderived fragments in senescenceaccelerated mouse prone 8 brain. Aging. 2019;11(22):10485-98.

34. Shen L, Tan Z, Gan M, Li Q, Chen L, Niu L, Jiang D, Zhao Y, Wang J, Li X, et al. tRNA-derived small non-coding RNAs as novel epigenetic molecules regulating adipogenesis. Biomolecules. 2019;9(7):274.

35. Chen $Y$, Wang $X$. miRDB: an online database for prediction of functional microRNA targets. Nucleic Acids Res. 2020;48(D1):D127-31.

36. O'Leary CE, Riling CR, Spruce LA, Ding H, Kumar S, Deng G, Liu Y, Seeholzer SH, Oliver PM. Ndfip-mediated degradation of Jak1 tunes cytokine signalling to limit expansion of CD4+ effector T cells. Nat Commun. 2016;7:11226
37. Mund T, Pelham HR. Regulation of PTEN/Akt and MAP kinase signaling pathways by the ubiquitin ligase activators Ndfip1 and Ndfip2. Proc Natl Acad Sci U S A. 2010;107(25):11429-34.

38. Cho H, Lee W, Kim GW, Lee SH, Moon JS, Kim M, Kim HS, Oh JW. Regulation of La/SSB-dependent viral gene expression by pre-tRNA 3'trailerderived tRNA fragments. Nucleic Acids Res. 2019;47(18):9888-901.

39. Selitsky SR, Baran-Gale J, Honda M, Yamane D, Masaki T, Fannin EE, Guerra B, Shirasaki T, Shimakami T, Kaneko S, et al. Small tRNA-derived RNAs are increased and more abundant than microRNAs in chronic hepatitis B and C. Sci Rep. 2015;5:7675.

40. Honda S, Loher P, Shigematsu M, Palazzo JP, Suzuki R, Imoto I, Rigoutsos I, Kirino Y. Sex hormone-dependent tRNA halves enhance cell proliferation in breast and prostate cancers. Proc Natl Acad Sci U S A. 2015;112(29):E3816-3825.

41. Zhang F, Shi J, Wu Z, Gao P, Zhang W, Qu B, Wang X, Song Y, Wang Z. A 3'-tRNA-derived fragment enhances cell proliferation, migration and invasion in gastric cancer by targeting FBXO47. Arch Biochem Biophys. 2020;690:108467.

42. Farina NH, Scalia S, Adams CE, Hong D, Fritz AJ, Messier TL, Balatti V, Veneziano D, Lian JB, Croce CM, et al. Identification of tRNA-derived small RNA (tsRNA) responsive to the tumor suppressor, RUNX1, in breast cancer. J Cell Physiol. 2020;235(6):5318-27.

43. Magee R, Rigoutsos I. On the expanding roles of tRNA fragments in modulating cell behavior. Nucleic Acids Res. 2020:48(17):9433-48.

44. Boskovic A, Bing XY, Kaymak E, Rando OJ. Control of noncoding RNA production and histone levels by a 5'tRNA fragment. Genes Dev. 2020;34(1-2):118-31.

45. Mo D, He F, Zheng J, Chen H, Tang L, Yan F. tRNA-derived fragment tRF-17-79MP9PP attenuates cell invasion and migration via THBS1/TGFbeta1/Smad3 axis in breast cancer. Front Oncol. 2021;11:656078.

46. Blanco S, Bandiera R, Popis M, Hussain S, Lombard P, Aleksic J, Sajini A, Tanna H, Cortes-Garrido R, Gkatza N, et al. Stem cell function and stress response are controlled by protein synthesis. Nature. 2016;534(7607):335-40.

47. Guzzi N, Ciesla M, Ngoc PCT, Lang S, Arora S, Dimitriou M, Pimkova $\mathrm{K}$, Sommarin MNE, Munita R, Lubas M et al. Pseudouridylation of tRNA-derived fragments steers translational control in stem cells. Cell 2018;173(5):1204-1216 e1226.

48. Dimri M, Humphries A, Laknaur A, Elattar S, Lee TJ, Sharma A, Kolhe R, Satyanarayana A. NAD(P)H quinone dehydrogenase 1 ablation inhibits activation of the phosphoinositide 3-kinase/Akt serine/threonine kinase and mitogen-activated protein kinase/extracellular signal-regulated kinase pathways and blocks metabolic adaptation in hepatocellular carcinoma. Hepatology. 2020;71(2):549-68.

49. Rebouissou S, Nault JC. Advances in molecular classification and precision oncology in hepatocellular carcinoma. J Hepatol. 2020;72(2):215-29.

\section{Publisher's Note}

Springer Nature remains neutral with regard to jurisdictional claims in published maps and institutional affiliations.
Ready to submit your research? Choose BMC and benefit from:

- fast, convenient online submission

- thorough peer review by experienced researchers in your field

- rapid publication on acceptance

- support for research data, including large and complex data types

- gold Open Access which fosters wider collaboration and increased citations

- maximum visibility for your research: over 100M website views per year

At $\mathrm{BMC}$, research is always in progress.

Learn more biomedcentral.com/submissions 